\title{
Linear Sequence Epitope
}

National Cancer Institute

\section{Source}

National Cancer Institute. Linear Sequence Epitope. NCI Thesaurus. Code C13454.

An epitope composed of adjacent amino acids 